\title{
Ketidakpastian Pengukuran pada Karakteristik Material Magnet Permanen dengan Alat Ukur Permagraph
}

\section{Measurement Uncertainty on The Characteristic of Permanent Magnetic Materials by Permagraph Instrument}

\author{
Tony Kristiantoro* , Novrita Idayanti, Nanang Sudrajat , Ardita Septiani, Dadang \\ Mulyadi dan Dedi
}

Pusat Penelitian Elektronika dan Telekomunikasi, Lembaga Ilmu Pengetahuan Indonesia. Komp. LIPI Gd 20, Jl Sangkuriang 21/54D, Bandung 40135, Indonesia

\begin{abstract}
Abstrak
Telah dilakukan perhitungan nilai ketidakpastian pengukuran pada karakteristik material magnet permanen menggunakan alat ukur Permagraph Magnet Physik Germany. Karakteristik magnet yang diukur adalah induksi remanen, $\mathrm{Br}(\mathrm{kG})$, gaya koersifitas induksi, $\mathrm{HcB}(\mathrm{kOe})$, gaya koersifitas polarisasi, HcJ (kOe), kuat medan remanen kiri, Hknee (kOe), produk energi maksimum, BHmax (MGOe), kuat medan produk energi maksimum, $\mathrm{Ha}(\mathrm{kOe})$, magnetik fluks, $\mathrm{Ba}(\mathrm{kG})$, kuat medan maksimum, Hmax (kOe). Sebelum menentukan nilai ketidakpastian dengan permagraph terlebih dahulu ditentukan nilai ketidakpastian dengan alat penunjang, yaitu jangka sorong dan neraca analitik. Selanjutnya akan didapat nilai ketidakpastian gabungan. Metoda ketidakpastian yang digunakan adalah dengan cara statistik dan berlaku hanya untuk serangkaian observasi. Penentuan nilai ketidakpastian dilakukan dengan cara melakukan pengukuran yang berulang sebanyak sepuluh kali terhadap sampel yang sama. Metoda ini mengacu kepada ISO GUM dengan menggunakan evaluasi tipe A. Nilai ketidakpastian yang didapat untuk pengukuran dengan jangka sorong adalah $\pm 0,0329 \mathrm{~cm}$, neraca analitik $\pm 0,0528$ gr, dan untuk karakteristik magnet $\mathrm{Br} \pm 0,0648$ $\mathrm{kG}, \mathrm{HcB} \pm 0,0632 \mathrm{kOe}, \mathrm{HcJ} \pm 0,0628 \mathrm{kOe}$, Hknee $\pm 0,0643 \mathrm{kOe}, \mathrm{BHmax} \pm 0,0631 \mathrm{MGOe}, \mathrm{Ha} \pm 0,1213 \mathrm{kOe}, \mathrm{Ba} \pm 0,0664 \mathrm{kG}$, Hmax $\pm 0,0627 \mathrm{kOe}$.
\end{abstract}

Kata kunci : nilai ketidakpastian, karakteristik magnet permanen, permagraph

\section{Abstract}

The prediction on the value of uncertainty on magnetic materials characterizations have been done by using Permagraph Magnet Physik Germany instrument. The magnetic properties that were measured are remanence induction, $\mathrm{Br}(\mathrm{k} G)$, coercive force of flux density, $\mathrm{HcB}(\mathrm{kOe})$, coercive force of polarization, $\mathrm{HcJ}(\mathrm{kOe})$, field strength at remanence left, Hknee (kOe), energy product maximum, $\mathrm{BHmax}$ (MGOe), field strength at maximum energy product, $\mathrm{Ha}(\mathrm{kOe})$, magnetic flux, Ba ( $\mathrm{kG}$ ), maximum field strength, Hmax $(\mathrm{kOe})$. Before determined the uncertainty value of permagraph, it must first determine the uncertainty value of the instrument's digital calipers and analytical balance. The uncertainty method that was used in this observation is statistical method and applies only to a series of observations. Determination of the value of uncertainty by performing repeated measurements at the same sample as much as ten times. This method is based on ISO GUM using the evaluation type A. Uncertainty of the values obtained for digital calipers $\pm 0.0329 \mathrm{~cm}$, analitycal balance $\pm 0.0528 \mathrm{gr}$, and magnetic characterizations $\mathrm{Br} \pm 0.0648 \mathrm{kG}, \mathrm{HcB} \pm 0.0632 \mathrm{kOe}$, HcJ $\pm 0.0628 \mathrm{kOe}$, Hknee $\pm 0.0643 \mathrm{kOe}, \mathrm{BHmax} \pm 0.0631 \mathrm{MGOe}$, Ha \pm 0.1213 kOe, Ba \pm 0.0664 kG, Hmax \pm 0.0627 kOe.

Keywords : uncertainty value, characteristic of permanent magnet, permagraph

\section{PEndahuluan}

Alat ukur permagraph adalah salah satu instrumen uji yang dimiliki oleh laboratorium bidang uji bahan magnet Puslit Elektronika dan Telekomunikasi (PPET) LIPI. Alat ini berfungsi untuk menguji karakteristik magnet pada material magnet permanen seperti nilai induksi remanen, koersifitas dan kuat medan maksimum. Alat uji permagraph sangat mendukung kegiatan penelitian magnet di PPET. Selain itu, permagraph juga dapat digunakan untuk pengujian dari

\footnotetext{
* Corresponding Author.

Email: tony001@lipi.go.id

Received: November 24, 2016; Revised: December 5, 2016

Accepted: December 5, 2016

Published: December 15, 2016

(C) 2016 PPET - LIPI

doi: $10.14203 /$ jet.v16.1-6
}

instansi lain seperti untuk penelitian di universitas dan produk komersial dari industri. Untuk mendukung hasil penelitian yang tepat dan akurat, maka diperlukan ketelitian dan kecermatan dalam menyajikan hasil pengujian dengan cara menentukan rentang nilai ukur yang disebut nilai ketidakpastian. Pengukuran dan pengujian belum dinyatakan lengkap tanpa nilai ketidakpastian. Semakin kecil nilai ketidakpastian maka semakin baik hasil penelitian atau pengujian [1].

Pada saat ini ketidakpastian pengukuran adalah merupakan salah satu persyaratan yang ada di ISO 17025 dan ISO 15189 yang harus dilakukan dan dilapokan oleh laboratorium pengujian atau kalibrasi [2]. Dalam standar itu diatur bahwa laboratorium wajib mempunyai dan menerapkan prosedur untuk mengestimasi ketidakpastian pengukuran. Estimasi ketidakpastian tersebut harus wajar (reasonable) dan 
didasarkan pada pengetahuan atas unjuk kerja metode, dan harus menggunakan data-data yang diperoleh dari pengalaman sebelumya serta data validasi metode. Standar ini juga mensyaratkan bahwa hasil pengujian harus terhubung ke SI (satuan internasional) dengan mata rantai 3 yang tidak terputus [3] - [5]. Khusus untuk laboratorium penguji, di mana jika ketertelusuran ke satuan SI tidak mungkin atau tidak relevan, maka ketertelusuran dapat dilakukan ke bahan acuan bersertifikat (CRM), metode, atau standar konsensus yang disepakati [2].

Dalam makalah ini akan disampaikan cara penentuan nilai ketidakpastian pada material magnet permanen dengan alat ukur permagraph dengan menggunakan evaluasi tipe A yaitu dengan cara melakukan pengukuran berulang sebanyak $10 \mathrm{k}$ ali terhadap pengukuran dimensi, massa, volume, dan sifat magnet.

\section{TeOri Dasar}

Ketidakpastian adalah suatu parameter yang menetapkan rentang nilai yang di dalamnya diperkirakan nilai benar yang diukur berada, seperti diilustrasikan pada Gambar 1.

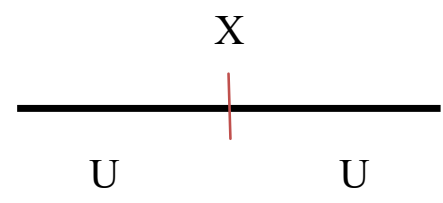

Gambar 1. Ilustrasi Konsep Ketidakpastian, di mana nilai X adalah nilai benar dan U adalah nilai ketidakpastiannya [6].

Menghitung rentang tersebut dikenal sebagai pengukuran ketidakpastian. Konsep ketidakpastian sangat penting untuk hasil pengukuran karena Nilai ketidakpastian menyatakan mutu hasil pengukuran atau pengujian. Pengukuran dan pengujian belum dinyatakan lengkap tanpa nilai ketidakpastian. Semakin kecil nilai ketidakpastian maka semakin akurat dan presisi hasil penelitian atau pengujian yang dilakukan. Keakuratan adalah kedekatan kesesuaian antara hasil pengukuran dengan nilai benar dari kuantitas yang diukur. Akurasi ini menyatakan ukuran seberapa dekat hasil pengukuran terhadap nilai benar yang diperkirakan. Sedangkan presisi adalah kedekatan suatu rangkaian pengukuran berulang satu sama lain. Presisi merupakan ukuran penyebaran/dispersi suatu kumpulan hasil pengukuran. Di samping itu presisi diterapkan pada pengukuran berulang tanpa menghiraukan letak nilai rata-rata terhadap nilai benar [7] - [9].

Banyak faktor yang dapat mempengaruhi nilai ketidakpastian. Beberapa penyebab ketidakpastian tersebut antara lain adanya Nilai Skala Terkecil (NST), kesalahan kalibrasi, kesalahan titik nol, kesalahan paralaks, fluktuasi parameter pengukuran, metoda sampling, homogenitas sampel, kondisi alat uji, ketidaksempurnaan metoda pengujian/pengukuran, pengaruh personil, dan kondisi lingkungan [10].

Sumber-sumber ketidakpastian harus diidentifikasi secara individual sebelum menentukan ketidakpastian pengukuran secara menyeluruh. Ketidakpastian yang bersumber dari individual akan melalui 2 tipe evaluasi yaitu evaluasi tipe A dan evaluasi tipe B [9].

\section{1) Evaluasi tipe $A$}

- Merupakan evaluasi komponen acak (random)

- Nilai ketidakpastian diperoleh dari pengukuran berulang dengan eksperimen

- Nilai ketidakpastian baku $=\mu=$ deviasi standar

\section{2) Evaluasi tipe $B$}

- Merupakan evaluasi komponen random dan sistematik.

- Berdasarkan pengetahuan dan pengalaman.

- Nilai ketidakpastian diperoleh dari sumber informasi, seperti: sertifikat kalibrasi, spesifikasi alat/bahan, handbook, dan katalog.

Ketidakpastian dibedakan menjadi dua, yaitu ketidakpastian mutlak dan relatif. Masing-masing ketidakpastian dapat digunakan dalam pengukuran tunggal dan berulang.

\section{A. Ketidakpastian Mutlak}

Suatu nilai ketidakpastian yang disebabkan karena keterbatasan alat ukur itu sendiri. Pada pengukuran tunggal, cara untuk melakukannya adalah sebagai berikut:

- Kumpulkan sejumlah hasil pengukuran variable x. Misalnya $n$ buah, yaitu x1, x2, x3, .. xn

- Cari nilai rata-ratanya yaitu $x-b a r$ $\mathrm{x}-\mathrm{bar}=(\mathrm{x} 1+\mathrm{x} 2+\ldots+\mathrm{xn}) / \mathrm{n}$

- Tentukan $\mathrm{x}-\max$ dan $\mathrm{x}-\min$ dari kumpulan data $\mathrm{x}$ tersebut dan ketidakpastiannya dapat dituliskan

$$
\Delta \mathrm{x}=(\mathrm{x} \max -\mathrm{x} \min ) / 2
$$

- Penulisan hasilnya sebagai berikut:

$$
\mathrm{x}=\mathrm{x}-\mathrm{bar} \pm \Delta \mathrm{x}
$$

\section{B. Standar Deviasi}

Bila dalam pengamatan dilakukan $\mathrm{n}$ kali pengukuran dari besaran $\mathrm{x} d$ an terkumpul data $\mathrm{x} 1, \mathrm{x} 2$, $\mathrm{x} 3, \ldots \mathrm{xn}$, maka xn adalah rata-rata dari besaran.

$$
\sigma=\sqrt{\frac{1}{N}\left[\left(I_{1}-\mu\right)^{2}+\cdots+\left(I_{N}-\mu\right)^{2}\right]}
$$

di mana $\mu=\frac{1}{N}\left(x_{1}+\cdots+x_{N}\right)$

$$
\sigma=\sqrt{N \sum_{i=1}^{N}\left(x_{1}-\mu\right)^{2}}
$$

di mana $\mu=\frac{1}{N} \sum_{i=1}^{N} x_{i}$

Kesalahan dari nilai rata-rata ini terhadap nilai sebenarnya besaran $\mathrm{x}$ dinyatakan oleh standar deviasi. Standar deviasi diberikan oleh persamaan diatas, sehingga kita hanya dapat menyatakan bahwa nilai benar dari besaran $\mathrm{x}$ terletak dalam selang $(\mathrm{x}-\sigma)$ sampai $(\mathrm{x}+\sigma)$. Dan untuk penulisan hasil pengukurannya adalah $\mathrm{x}=\mathrm{x} \pm \sigma$. 


\section{Ketidakpastian Relatif}

Ketidakpastian Relatif adalah ketidakpastian yang dibandingkan dengan hasil pengukuran. Hubungan hasil pengukurun terhadap KTP (ketidakpastian) yaitu:

$$
\mathrm{KTP} \text { relatif }=\Delta \mathrm{x} / \mathrm{x}
$$

Apabila menggunakan KTP relatif maka hasil pengukuran dilaporkan sebagai

$$
\mathrm{X}=\mathrm{x} \pm(\text { KTP relatif } \mathrm{x} 100 \%)
$$

\section{METODOLOGI}

Ada beberapa tahap persiapan yang harus dilakukan sebelum sampel magnet diukur dengan permagraph, yaitu pengukuran data dimensi dan densitas. Data tersebut merupakan input data pada alat yang akan mempengaruhi karakteristik magnet yang diukur. Pengukuran dimensi dilakukan dengan jangka sorong dan nilai densitas dapat diketahui dengan penentuan massa sampel dengan neraca analitik. Pengukuran dengan kedua alat tersebut juga memiliki nilai ketidakpastian, sehingga perlu dilakukan pengukuran berulang untuk mendapatkan nilai ketidakpastiannya.

\section{A. Penanganan Sampel Uji.}

Sampel uji berupa bahan magnet hasil penelitian harus dihindari dari tertukarnya sampel dan kerusakan yang akan mempengaruhi hasil uji. Penanganan sampel dilakukan dengan cara:

o Menempatkan sampel di dalam wadah plastik sampel.

o Menyimpan ditempat yang aman seperti dalam desikator atau wadah agar tidak jatuh.

o Memberi nomor atau label untuk menghindari tertukarnya sampel yang satu dengan yang lainnya.

\section{B. Pengukuran Dimensi}

Bahan magnet disiapkan dengan bentuk bulat dengan dimensi yang beraturan. Dimensi sampel magnet yang diukur adalah diameter dan tebal. Dimensi sampel dapat dilihat pada Gambar 2.

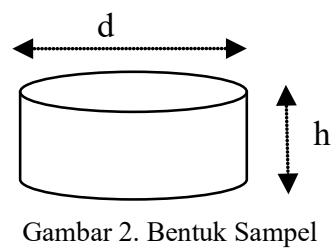

Dari data diameter (d) dan tinggi sampel (h), dapat dihitung volume sampel dengan persamaan :

$$
V\left(\mathrm{~cm}^{3}\right)=0,25 \pi h d^{2}
$$

Pengukuran dimensi untuk diameter dan tebal dilakukan sebanyak sepuluh kali. Nilai ketidakpastian dari pengukuran jangka sorong disebut U1. Jangka sorong yang digunakan pada penelitian ini dapat dilihat pada Gambar 3.

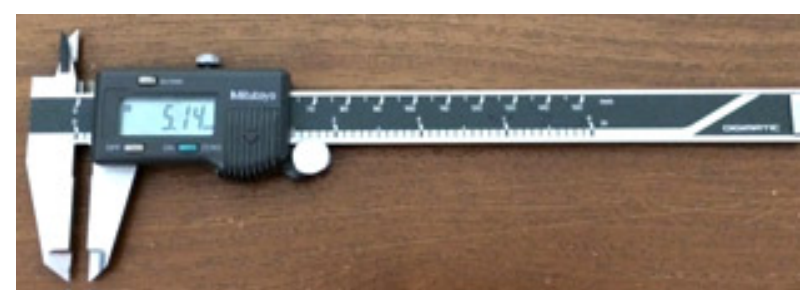

Gambar 3. Jangka Sorong

\section{Pengukuran Berat dan Densitas}

Berat sampel atau massa diukur menggunakan neraca analitik digital untuk menentukan nilai densitas. Perhitungan densitas dengan menggunakan persamaan berikut [2]:

$$
\rho\left(\mathrm{g} / \mathrm{cm}^{3}\right)=\text { massa } / \text { volume }
$$

Berat sampel diukur dengan menggunakan neraca analitik seperti Gambar 4 di bawah ini.

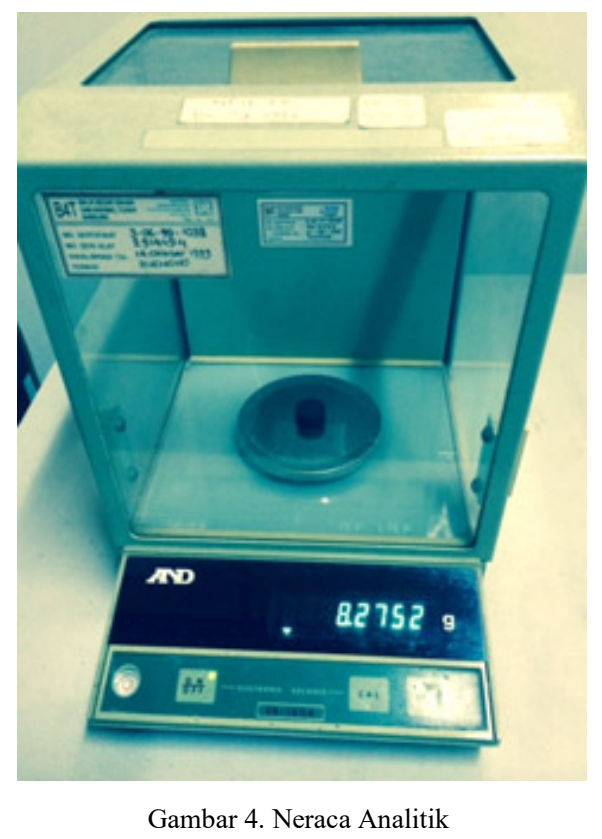

\section{Pengukuran Sifat Magnet}

Pengukuran sifat magnet dilakukan menggunakan permagraph. Karakteristik magnet yang akan terukur di antaranya adalah: induksi remanen, koersifitas, kuat medan maksimum, dan lain-lain. Pengukuran dilakukan secara berulang sebanyak sepuluh kali untuk mendapatkan nilai ketidakpastian. Alat ukur permagraph dapat dilihat pada Gambar 5.

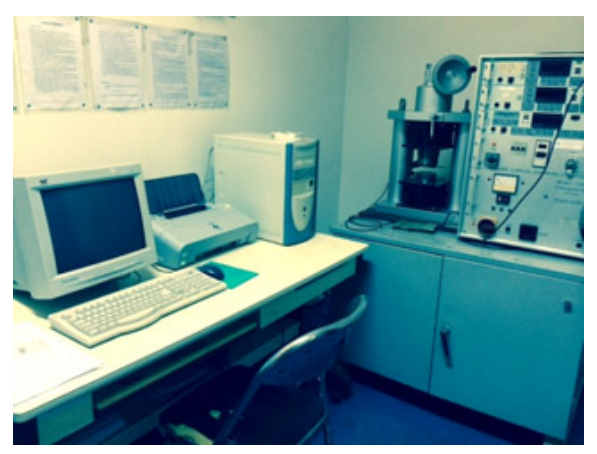

Gambar 5. Permagraph 
Sampel ditempatkan di alat dengan diberikan medan magnet dari luar.

Untuk menentukan nilai ketidakpastian digunakan rumus-rumus sebagai berikut [7], [9]:

- Menghitung standar deviasi :

$$
\sigma=\sqrt{\sum x^{2}-\frac{\left(\sum x^{2}\right)}{N}}
$$

- $\quad$ Menghitung rata-rata (m) :

$$
m=\frac{\sum x}{N}
$$

- Menghitung nilai ketidakpastian :

$$
U=\frac{\sigma}{\sqrt{n}}
$$

- Ketidakpastian gabungan :

$$
\begin{aligned}
& U_{g a b}^{2}=U_{1}^{2}+U_{2}^{2}+U_{3}^{2} \\
& U_{g a b}^{2}=\sqrt{U_{1}^{2}+U_{2}^{2}+U_{3}^{2}}
\end{aligned}
$$

Keterangan :

$$
\begin{aligned}
& \mathrm{X} \text { : data } \\
& \mathrm{m} \text { : nilai rata - rata } \\
& \mathrm{N} \text { : jumlah / banyaknya pengukuran } \\
& \sigma \quad: \quad \text { standar deviasi } \\
& \mathrm{U} \quad \text { : nilai ketidakpastian } \\
& \mathrm{U}_{\text {gab }} \text { : nilai ketidakpastian gabungan } \\
& \mathrm{U}_{1} \text { : nilai ketidakpastian untuk jangka } \\
& \text { sorong } \\
& \mathrm{U}_{2} \text { : nilai ketidakpastian untuk neraca }
\end{aligned}
$$

Setelah masing-masing nilai ketidakpastian jangka sorong, neraca analitik dan permagraph diketahui, maka dihitung nilai ketidakpastian gabungan.

\section{Hasil dan Pembahasan}

\section{A. Hasil Pengukuran Dimensi}

Data hasil pengukuran dimensi berupa diameter dan tebal sampel dapat dilihat pada Tabel 1. Data dari tabel menunjukkan bahwa perubahan angka terjadi pada digit ketiga dan keempat. Akan tetapi perubahan pada digit keempat lebih banyak terjadi. Standar deviasi yang didapat adalah $0,0075 \mathrm{~cm}$ untuk pengukuran diameter dan $0,0033 \mathrm{~cm}$ untuk pengukuran tebal. Angka ketidakpastian gabungan yang didapat untuk pengukuran dengan jangka sorong adalah $0,0329 \mathrm{~cm}$.

Nilai ini dianggap cukup baik untuk sebuah nilai ketidakpastian karena didapat dari hasil pengukuran berulang sebanyak sepuluh kali dengan perubahan angka di desimal kedua. Ketelitian dan keakuratan alat jangka sorong yang merupakan alat penunjang untuk penentuan karakteristik magnet keras dinilai cukup akurat. Jangka sorong di laboratorium bidang uji bahan magnet PPET-LIPI selalu dikalibrasi secara berkala setiap 2 tahun sekali oleh lembaga kalibrasi terakreditasi. Dari nilai rata-rata pada Tabel 1 dan menggunakan Persamaan 6 maka diperoleh volume sampel 2,0582 $\mathrm{cm}^{3}$.
TABEL 1

PENGUKURAN DiMENSI

\begin{tabular}{|l|l|l|}
\hline \multirow{2}{*}{ No } & \multicolumn{2}{|c|}{ Dimensi (cm) } \\
\cline { 2 - 3 } & Diameter (d) & Tebal (h) \\
\hline 1 & 1,738 & 0,868 \\
\hline 2 & 1,740 & 0,869 \\
\hline 3 & 1,741 & 0,866 \\
\hline 4 & 1,743 & 0,866 \\
\hline 5 & 1,743 & 0,866 \\
\hline 6 & 1,741 & 0,869 \\
\hline 7 & 1,738 & 0,868 \\
\hline 8 & 1,738 & 0,868 \\
\hline 9 & 1,735 & 0,867 \\
\hline 10 & 1,739 & 0,867 \\
\hline$\sigma$ & 0,0075 & 0,0033 \\
\hline$m$ & 1,7390 & 0,867 \\
\hline$U$ & 0,0274 & 0,0182 \\
\hline $\mathbf{U}_{\text {gab }}$ & & $\mathbf{0 , 0 3 2 9}$ \\
\hline & & \multicolumn{2}{|l}{} \\
\hline
\end{tabular}

\section{B. Hasil Pengukuran Berat}

Data hasil pengukuran berat sampel dapat dilihat pada Tabel 2. Penentuan massa atau berat dengan neraca analitik dilakukan berulang sebanyak sepuluh kali. Nilai ketidakpastian yang didapat adalah 0,0528 gr. Densitas sampel dapat diketahui dengan cara menggunakan Persamaan 7 sehingga diperoleh nilainya sebesar $4,0205 \mathrm{~g} / \mathrm{cm}^{3}$.

TABEL 2

\begin{tabular}{|l|l|}
\hline \multicolumn{1}{|c|}{ PENGUKURAN BERAT } \\
\hline 1 & \multicolumn{1}{|c|}{ Massa (gr) } \\
\hline 2 & 8,2740 \\
\hline 3 & 8,2742 \\
\hline 4 & 8,2745 \\
\hline 5 & 8,2743 \\
\hline 6 & 8,2749 \\
\hline 7 & 8,2747 \\
\hline 8 & 8,2749 \\
\hline 9 & 8,2747 \\
\hline 10 & 8,2746 \\
\hline$\sigma$ & 0,0279 \\
\hline$m$ & 8,275 \\
\hline $\mathbf{U}$ & $\mathbf{0 , 0 5 2 8}$ \\
\hline
\end{tabular}

Densitas tersebut menunjukkan bahwa sampel yang digunakan pada percobaan adalah sejenis magnet permanen ferit. Dari literatur adalah benar bahwa densitas ferit berkisar antara $4-5 \mathrm{~g} / \mathrm{cm}^{3}$. Neraca analitik juga dikalibrasi secara berkala setiap 2 tahun sekali. Penggunaan alat jangka sorong dan neraca analitik yang berfungsi dengan baik dan akurat dapat membantu menentukan nilai densitas suatu sampel. 


\section{Hasil Pengukuran Sifat Magnet}

Pengukuran sifat magnet dilakukan secara berulang sebanyak sepuluh kali. Salah satu contoh kurva hysteresis yang telah digambar ulang dengan kurva excel dapat dilihat pada Gambar 6.

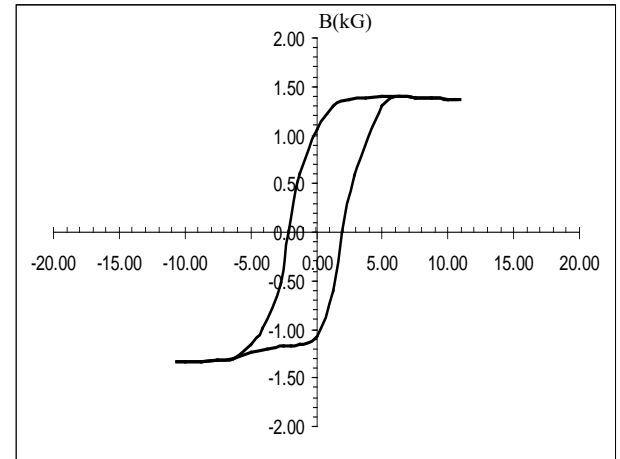

Gambar 6. Kurva Hysteresis

Dari kurva hysteresis akan didapat karakteristik magnet sebagai berikut:

- Br : Induksi Remanen / Remanence Induction (kG)

- HcB : Gaya Koersifitas Induksi / Coercive Force of Flux Density (kOe)

- HcJ : Gaya Koersifitas Polarisasi / Coercive Force of Polarization (kOe)

- Hknee : Kuat Medan Remanen Kiri / Field Strength at Remanence Left (kOe)

- BHmax : Produk Energi Maksimum / Energy Product Maximum (MGOe)

- Ha : Kuat Medan Produk Energi Maksimum / Field Strength at Maximum Energy Product (kOe)

- Ba : Flux Magnetik/Magnetic Flux (kG)

- Hmax : Kuat Medan Maksimum/ Field Strength at Maximum (kOe)

Data karakteristik magnet permanen yang diukur sebanyak 10 kali dapat dilihat pada Tabel 3 di bawah ini. Tabel 3 menunjukkan nilai ketidakpastian untuk masing-masing karakteristik magnet adalah sebagai berikut : Br dan Ba bernilai 0,0648 dan 0,0664 kG;
BHmax 0,0631 MGOe; HcB, HcJ, Hknee, dan Hmax hampir sama yaitu berkisar antara 0,0627 - 0,0643 kOe. Nilai karakteristik magnet juga relatif stabil. Akan tetapi nilai ketidakpastian untuk Ha berbeda, yaitu 0,1213 kOe. Dari hasil pengukuran berulang sebanyak sepuluh kali, nilai Ha tidak stabil dibandingkan dengan nilai karakteristik yang lain. Nilai berkisar antara 0,310 - 1,5 $\mathrm{kOe}$, dengan rata-rata yang didapat adalah $0,695 \mathrm{kOe}$. Bila diperhatikan ketidakstabilan ini bukanlah disebabkan karena ketidaktelitian alat, karena nilai karakteristik yang lain cukup stabil terhadap pengukuran berulang. Ketidakstabilan bisa disebabkan karena belum homogennya sampel magnet hasil percobaan yang digunakan. Ketidakhomogenan yang dimaksud adalah dari keseragaman batas dan besar butir, komposisi bahan, dan sifat magnet bahan. Nilai Ha adalah kuat medan energi produk maksimum yang dimiliki oleh bahan magnet, sehingga apabila kuat medan magnet dari luar diberikan kepada sampel yang kurang homogen akan menghasilkan nilai yang kurang stabil.

\section{KESIMPULAN}

Dari hasil pengukuran karakteristik magnet permanen menggunakan alat jangka sorong, neraca analitik, dan permagraph nilai ketidakpastian masingmasing alat dapat ditentukan melalui pengukuran berulang sebanyak sepuluh kali. Nilai ketidakpastian untuk jangka sorong adalah $0,0329 \mathrm{~cm}$; neraca analitik 0,0528 gr; Br dan Ba masing-masing 0,0648 dan 0,0664 kG; BHmax 0,0631 MGOe; HcB, HcJ, Hknee, dan Hmax hampir sama yaitu berkisar antara 0,0627 0,0643 kOe. Nilai karakteristik magnet juga relatif stabil. Akan tetapi nilai ketidakpastian untuk Ha berbeda, yaitu $0,1213 \mathrm{kOe}$.

Ketidakstabilan nilai pada karakteristik magnet $\mathrm{Ha}$ bukan disebabkan karena ketidakstabilan alat, akan tetapi disebabkan karena ketidakhomogenan sampel magnet permanen yang digunakan. Nilai-nilai yang didapat ini cukup kecil untuk sebuah nilai ketidakpastian, sehingga alat ukur permagraph beserta alat penunjang jangka sorong dan neraca analitik dianggap baik dan akurat.

TABEL 3

KARAKTERISTIK MAGNET PERMANEN

\begin{tabular}{|c|c|c|c|c|c|c|c|c|}
\hline \multirow{2}{*}{ No. } & $\mathbf{B r}$ & $\mathbf{H c B}$ & $\mathbf{H c J}$ & Hknee & BHmax & Ha & Ba & Hmax \\
\cline { 2 - 8 } & $\mathbf{( k G )}$ & $\mathbf{( k O e )}$ & $\mathbf{( k O e )}$ & $\mathbf{( k O e )}$ & $\mathbf{( M G O e )}$ & $\mathbf{( k O e )}$ & $\mathbf{( k G )}$ & $\mathbf{( k O e )}$ \\
\hline 1 & 1,52 & 0,337 & 0,45 & 0,067 & 0,14 & 0,56 & 0,25 & 11,6 \\
\hline 2 & 1,62 & 0,341 & 0,5 & 0,08 & 0,18 & 0,88 & 0,2 & 11,55 \\
\hline 3 & 1,54 & 0,334 & 0,488 & 0,076 & 0,15 & 0,74 & 0,2 & 11,6 \\
\hline 4 & 1,52 & 0,319 & 0,471 & 0,115 & 0,14 & 0,68 & 0,2 & 11,6 \\
\hline 5 & 1,52 & 0,329 & 0,486 & 0,11 & 0,14 & 0,68 & 0,2 & 11,6 \\
\hline 6 & 1,52 & 0,304 & 0,452 & 0,139 & 0,14 & 0,68 & 0,2 & 11,6 \\
\hline 7 & 1,48 & 0,319 & 0,471 & 0,088 & 0,14 & 0,56 & 0,25 & 11,6 \\
\hline 8 & 1,62 & 0,392 & 0,519 & 0,207 & 0,11 & 0,37 & 0,3 & 11,6 \\
\hline 9 & 1,55 & 0,375 & 0,497 & 0,131 & 0,09 & 0,31 & 0,3 & 11,6 \\
\hline 10 & 1,65 & 0,365 & 0,5 & 0,192 & 0,08 & 1,5 & 0,05 & 11,6 \\
\hline
\end{tabular}


Nilai ketidakpastian karakteristik magnet di laboratorium uji bidang magnet PPET-LIPI dapat menjamin mutu hasil pengujian untuk penelitian internal maupun untuk pengujian dari instansi eksternal.

\section{UCAPAN TERIMA KASIH}

Penelitian ini didanai oleh anggaran DIPA PPETLIPI tahun 2015.

\section{DAFTAR PUSTAKa}

[1] ISO/IEC, "General requirements for the competence of testing and calibration laboratories", in International Standard ISO/IEC 17025:2005, Switzerland, 2005.

[2] Y. Liu, "How to generate uncertain measures", in Proceedings of Tenth National Youth Conference on Information and Management Sciences, 2008, pp. 23-26.

[3] B. Liu, Uncertainty Theory, 2nd ed., Berlin: Springer-Verlag, 2007.

[4] B. Liu, "Some research problems in uncertainty theory", Journal of Uncertain Systems, vol. 3, no.1, pp. 3-10, 2009.

[5] ISO, "Guide to the expression of uncertainty in measurement", in Accred. Qual. Assur, Switzerland, 2002, pp 95-1001.

[6] S. Yohanes, "Estimasi ketidakpastian pengukuran/pengujian dalam pengukuran/pengujian kimia", Paper, 2010.

[7] Sunardi, T. S. Susann, N. Elin, "Ketidakpastian pengukuran pada metode AANC untuk analisis $\mathrm{N}, \mathrm{P}, \mathrm{K}, \mathrm{SI}, \mathrm{Al}, \mathrm{Cu}, \mathrm{Fe}$ dalam cuplikan sedimen", Prosiding PPI - PDIPTN, 2007.

[8] B. Muhammad. (2011, Januari). Dasar pengukuran dan ketidakpastian. [Online]. Available https:/alvinburhani.wordpress.com/2011/01/02/dasarpengukuran-ketidakpastian/

[9] Badan Standardisasi Nasional (BSN), Pengantar Standardisasi, Jakarta, 2009.

[10] Lansida. (2011, Januari). Estimasi ketidakpastian pengukuran. [Online]. Available : lansida.blogspot.co.id/2011/01/estimasiketidakpastian-pengukuran.html 